IZA DP No. 4212

Military Conscription and University Enrolment:

Evidence from Italy

Giorgio Di Pietro

June 2009 


\title{
Military Conscription and University Enrolment: Evidence from Italy
}

\author{
Giorgio Di Pietro \\ University of Westminster \\ and IZA
}

Discussion Paper No. 4212

June 2009

IZA
P.O. Box 7240
53072 Bonn
Germany

Phone: +49-228-3894-0

Fax: +49-228-3894-180

E-mail: iza@iza.org

\begin{abstract}
Any opinions expressed here are those of the author(s) and not those of IZA. Research published in this series may include views on policy, but the institute itself takes no institutional policy positions.

The Institute for the Study of Labor (IZA) in Bonn is a local and virtual international research center and a place of communication between science, politics and business. IZA is an independent nonprofit organization supported by Deutsche Post Foundation. The center is associated with the University of Bonn and offers a stimulating research environment through its international network, workshops and conferences, data service, project support, research visits and doctoral program. IZA engages in (i) original and internationally competitive research in all fields of labor economics, (ii) development of policy concepts, and (iii) dissemination of research results and concepts to the interested public.
\end{abstract}

IZA Discussion Papers often represent preliminary work and are circulated to encourage discussion. Citation of such a paper should account for its provisional character. A revised version may be available directly from the author. 


\title{
ABSTRACT
}

\section{Military Conscription and University Enrolment: Evidence from Italy}

\begin{abstract}
Given that a growing number of countries have abolished or are considering the abolition of military conscription, understanding the consequences of this measure is of increased importance. In this paper we study the effect of the suppression of compulsory military service on university enrolment in Italy using double and triple differences models. The empirical results show that there is no compelling evidence suggesting that the abolition of military conscription has a causal effect on university enrolment. However, although there is no significant overall effect, we find some evidence of heterogeneous effects. While this measure seems to increase university participation among individuals from more advantaged backgrounds, it appears to have a detrimental effect on the enrolment of those from less advantaged backgrounds.
\end{abstract}

JEL Classification: $\quad 120, \mathrm{~J} 24$

Keywords: compulsory military service, university enrolment

Corresponding author:

Giorgio Di Pietro

University of Westminster

Westminster Business School

Department of Economics and Quantitative Methods

35 Marylebone Road

NW1 5LS London

United Kingdom

E-mail: G.D.I.Pietro@westminster.ac.uk 


\section{Introduction}

A number of studies in the economics literature look at the effects of military conscription. While some of them (Angrist and Krueger, 1989; Angrist, 1990; Imbens and Wilbert van der Klaauw, 1995; Bauer et al., 2004) analyse the impact of serving in the military on individuals' subsequent earnings, others focus on the consequences of the suppression of compulsory military service (CMS) on schooling. These latter studies produce, however, mixed results.

Maurin and Xenogiani (2007) conclude that French young men who were affected by the 1997 military reform, which abolished CMS, have a lower educational attainment and a lower probability of successfully completing high school relative to their peers who were not at risk of service. This reform is found to have a detrimental effect especially on the educational outcomes of individuals from less advantaged socioeconomic backgrounds. Results from studies by Angrist and Krueger (1992) and Card and Lemieux (2001) can also be interpreted as supporting the hypothesis that the abolition of CMS may have an adverse effect on schooling. They find that in the US between 1965 and 1975 draft avoidance behaviours led to a rise in college enrolment and graduation rates, implicitly suggesting that these would have been lower in the absence of conscription.

On the other hand, findings from studies on the UK and Italy are at variance with those reported above. Buonanno (2006) shows that in the UK the abolition of military conscription has led to an increase in school attendance among men aged 18 or above. Additionally, his estimates indicate that individuals for whom the military service was not compulsory have, on average, 0.25 years of education more than those who were subject to CMS. Cipollone and Rosolia (2007) look at the consequences of exemption from CMS given to a few cohorts of men living in areas of southern Italy that were hit by an earthquake in 1980. They find that this exemption led to a 2 percentage points increase in male high school graduation rates.

In light of these mixed results, in this paper we attempt to provide new evidence on the relationship between education and the suppression of CMS. We extend earlier work of Cipollone and Rosolia (2007) on Italy in three main respects. First, while 
their analysis regards some parts of Italy, we look at the effects of the abolition of National Service in all the Italian territory. Second, our study uses very recent data as CMS was abolished in Italy in 2005. Third, whilst Cipollone and Rosolia (2007) examine how not being at risk of service has affected the choice to finish high school, we analyse the effect of the abolition of CMS on the university enrolment decision. Understanding the factors influencing the transition from secondary to tertiary education is very important given that there are relevant benefits associated with investment in higher education not only for individuals but also for society as a whole (Baum and Payea, 2004).

The abolition of military conscription may have conflicting effects on the decision to pursue education and in particular on that of enrolling at university. On the one hand, it may discourage male high school graduates from further investing in schooling since they no longer need to stay in education as a way to avoid immediate military service. As outlined by Maurin and Xenogiani (2007), many young men choose to defer the military service as long as they can, since this experience is perceived to be associated with several costs (e.g. living in a barrack, sharing a room with several other men and participating in military training and drills). Additionally, holding a university degree may significantly reduce these costs as university graduates are likely to be chosen for milder forms of national service.

On the other hand, however, the dismissal of CMS may induce more male high school graduates to invest in university education as this allows them to get returns from this investment over a longer period. Additionally, although male university and high school graduates may both benefit from the abolition of CMS as they can both enter into the labour market immediately after completing their studies, avoiding career interruptions is likely to bring more advantages to the former group relative to the latter $^{1}$. This is because the rate of depreciation of education is likely to increase with years of education (Neuman and Weiss, 1995) given that more educated individuals typically have jobs where technical and economic changes happen at a fast rate.

\footnotetext{
${ }^{1}$ The career interruption may last longer than the length of the military service as typically, due to bureaucratic reasons, there is a waiting period before men can actually start the service. Imbens and Wilbert van der Klaauw (1995) suggest that in the Netherlands the cost of doing the military service is approximately equivalent to the cost of losing two years of potential work experience.
} 
The remainder of this paper is as follows. In Section 2 we develop a simple model to investigate the effect of the abolition of CMS on the university enrolment decision. Section 3 briefly describes the institutional features of CMS in Italy before it was abolished. In Section 4 we outline the identification strategy used to determine the causal effect of the suppression of CMS on university enrolment. Section 5 presents the data employed in this study. In Section 6 empirical results are reported and discussed. Section 7 concludes.

\section{A simple theoretical framework}

Unlike previous studies on the effect of the abolition of CMS on education, in this paper we set up a simple theoretical framework in order to understand how not having to do the military service may influence the schooling decision of young male individuals. We adopt a human capital approach (Becker, 1964) and, given the purpose of this study, we focus our attention on the decision whether or not to enrol at university. Let's first analyse this choice in the presence of CMS. In such a case, the present value of the earnings stream for a male high school graduate who, at the age of 18 , chooses not to enrol at university is

(1) $P V^{H S}=\sum_{n=19}^{64} \frac{W^{H S}}{(1+r)^{n-18}}$

where the superscript HS refers to high school education, $\mathrm{r}$ is the discount rate and $\mathrm{W}$ is the yearly wage. Assuming that the military service lasts for one year, this individual is expected to earn $\mathrm{W}^{\mathrm{HS}}$ from age 19 until the age of retirement (i.e. 65).

If instead, the male high school graduate chooses to enrol at university, then the present value of the stream of his future incomes would be

(2) $P V^{U}=\sum_{n=24}^{64} \frac{W^{U}}{(1+r)^{n-18}}$

where the superscript $U$ refers to university education. Assuming that this individual is able to graduate in four years and that the military service still lasts for one year, he is expected to earn $\mathrm{W}^{\mathrm{U}}$ from age 24 until retirement. 
Now we look at what happens when CMS is abolished. In this circumstance, the present value of the earnings stream for a male high school graduate who, at the age of 18 , chooses not to enrol at university becomes

(3) $P V^{H S}=\sum_{n=18}^{64} \frac{W^{H S}}{(1+r)^{n-18}}$

If instead, after the suppression of CMS, the male high school graduate chooses to enrol at university, then the present value of the stream of his future incomes would become

(4) $P V^{U}=\sum_{n=23}^{64} \frac{W^{U}}{(1+r)^{n-18}}$

As one can see from Equations (3) and (4), the abolition of CMS brings financial benefits for the individual if he decides not to attend university as well as if he chooses to enrol at university.

In the presence of CMS, a male high school graduate will choose to enrol at university if:

$\sum_{n=24}^{64} \frac{W^{U}}{(1+r)^{n-18}}>\sum_{n=19}^{64} \frac{W^{H S}}{(1+r)^{n-18}}$

(5) $-\sum_{n=19}^{23} \frac{W^{H S}}{(1+r)^{n-18}}+\sum_{n=24}^{64} \frac{W^{U}-W^{H S}}{(1+r)^{n-18}}>0$

where $-\sum_{n=19}^{23} \frac{W^{H S}}{(1+r)^{n-18}}$ represents the opportunity cost of going to university ${ }^{2}$

and $\sum_{n=24}^{64} \frac{W^{U}-W^{H S}}{(1+r)^{n-18}}$ is the gain from having a higher wage afterwards.

In the absence of CMS, a male high school graduate will choose to enrol at university if:

$\sum_{n=23}^{64} \frac{W^{U}}{(1+r)^{n-18}}>\sum_{n=18}^{64} \frac{W^{H S}}{(1+r)^{n-18}}$

(6) $-\sum_{n=18}^{22} \frac{W^{H S}}{(1+r)^{n-18}}+\sum_{n=23}^{64} \frac{W^{U}-W^{H S}}{(1+r)^{n-18}}>0$

where $-\sum_{n=18}^{22} \frac{W^{H S}}{(1+r)^{n-18}}$ represents the opportunity cost of going to university

\footnotetext{
${ }^{2}$ It is assumed that the direct cost of university education is zero.
} 
and $\sum_{n=23}^{64} \frac{W^{U}-W^{H S}}{(1+r)^{n-18}}$ is the gain from having a higher wage afterwards.

This simple model shows that the of abolition of CMS encourages a male high school graduate to enrol at university if the left hand side of Equation (6) is bigger than the left hand side of Equation (5):

$$
\begin{aligned}
& -\sum_{n=18}^{22} \frac{W^{H S}}{(1+r)^{n-18}}+\sum_{n=23}^{64} \frac{W^{U}-W^{H S}}{(1+r)^{n-18}}>-\sum_{n=19}^{23} \frac{W^{H S}}{(1+r)^{n-18}}+\sum_{n=24}^{64} \frac{W^{U}-W^{H S}}{(1+r)^{n-18}} \\
& -W^{H S}+\frac{W^{H S}}{(1+r)^{5}}+\frac{W^{U}-W^{H S}}{(1+r)^{5}}>0 \\
& \text { (7) } W^{H S}\left(\frac{1}{(1+r)^{5}}-1\right)+\frac{W^{U}-W^{H S}}{(1+r)^{5}}>0
\end{aligned}
$$

The condition (7) can be re-written as:

(8) $W^{U}>(1+r)^{5} W^{H S}$

From Equation (8) it emerges that the suppression of CMS will have a positive impact on the university enrolment decision if

1) the individual time discount rate is small enough

2) the university wage is large enough relative to the high school wage

\section{Compulsory military service in Italy}

In Italy CMS was abolished in 2005 following a military reform (Legge Martino) approved by the Parliament in July 2004. According to this reform, men born after $1^{\text {st }}$ January 1986 are no longer subject to $\mathrm{CMS}^{3}$. The rationale for this was to move toward a professional military in line with several other countries including the US and the UK.

In Italy the procedures for the selection of conscripts were similar to those implemented in other countries such as Germany and the Netherlands. All young men were called for medical and psychological examinations shortly after or shortly before they turned 18. These examinations typically lasted between 2 and 3 days, at the end

\footnotetext{
${ }^{3}$ Whilst in the early 1980s the length of service was 12 months, in the late 1990s this was reduced to 10 months.
} 
of which period potential recruits were split into three main groups: a) those who had a good health status and no psychological problems were declared to be suitable to do the military service; b) those who had serious health or physiological problems were immediately exempt from the military service; c) those who needed to undertake further medical and psychological examinations. Based on the results of these additional examinations, they were declared to be fit to serve or not. Finally, even if on the grounds of medical and psychological examinations a young man was found to be suitable to do the military service, he could still have been exempt for special reasons ${ }^{4}$. As outlined by Cipollone and Rosolia (2007), in Italy "the reasons for exemption from service were strictly coded and restrictive”.

Men who at the age of 18 were in school could defer military service, provided that they could successfully complete high school by the age of 22. Male high school graduates who enrolled at university immediately after completing their studies could also obtain one-year deferment. Those students performing well at university could obtain successive one-year deferments, provided that they could graduate by the age of 27.

The 2004 military reform also put an end to conscientious objectors. Since 1972, men, who were declared to be fit to serve in the military, had the possibility to become conscientious objectors. Conscientious objectors were freed from military service but they had to perform public service for a period of time typically longer than that associated with the military service. On the other hand, they enjoyed considerable freedom in selecting the institution where to the perform public service.

\section{Identification strategy}

In this Section we sketch the methodological approach used to estimate the effect of the abolition of CMS on university enrolment. Gender and the date of birth jointly determine whether a high school graduate is affected by the abolition of CMS. Women are exempt from military service in Italy. Only those male high school graduates born after $1^{\text {st }}$ January 1986 benefit from the suppression of CMS. Hence, to estimate the effect of the abolition of CMS on the decision to attend university, our

\footnotetext{
${ }^{4}$ For instance, if he was orphan from both parents, son or brother of a soldier died in war or widower with dependant child
} 
basic strategy is to track the difference in university enrolment between male high school graduates born after and before $1^{\text {st }}$ January 1986, and then compare this with the corresponding difference between similar female high school graduates. This comparison, which generates the so-called difference-in-differences (DiD) or doubledifference estimator, allows us to control for unobserved age-group specific effects as well as for common macro-effects. Using a sample of high school graduates who successfully completed their studies in 2004, one may observe that those born after $1^{\text {st }}$ January 1986 were 18 years old or less at that time. Thus our DiD estimator is:

(9) $\Delta_{2004}^{2}=\left(E_{M}^{\leq 18}-E_{M}^{\geq 19}\right)-\left(E_{F}^{\leq 18}-E_{F}^{\geq 19}\right)$

where subscripts $\mathrm{M}$ and $\mathrm{F}$ denote males and females, respectively. Whilst $E^{\leq 18}$ represents the university enrolment choice of individuals aged 18 or less when they finished high school, $E^{\geq 19}$ indicates the university enrolment choice of individuals aged 19 or more when they finished high school. The subscript 2004 indicates that we use a sample of people who finished high school in 2004.

Adjusting the DiD estimator for observables requires estimating the following equation:

$$
E_{i}=\alpha+\beta_{0} X_{i}+\beta_{1} M_{i}+\beta_{2} T_{i}+\beta_{3} T_{i} M_{i}+\varepsilon_{i}
$$

where $E_{\mathrm{i}}$ is the university enrolment choice observed for high school graduate $\mathrm{i}$. It is a dichotomous variable that is equal to 1 if the high school graduate enrols at university, and 0 otherwise. $\mathrm{X}$ is a vector of individual and family characteristics that are thought to influence the university enrolment decision. $\mathrm{M}$ is a dummy taking the value 1 if the high school graduate is male, and 0 otherwise. $\mathrm{T}$ is a dummy variable taking the value 1 if the individual finished high school when he/she was 18 years old or younger, and 0 otherwise; and $\varepsilon$ is the usual error term.

The DiD estimator is the coefficient $\beta_{3}$. It tests whether, following the abolition of CMS, the difference in university enrolment between high school graduates aged 18 or less and their peers aged 19 or above varies systematically across gender. $\beta_{3}$ identifies the true effect of the suppression of CMS assuming there are no shocks 
taking place coincidentally at the same as the 2004 military reform and affecting only the university enrolment decision of male high school graduates aged 18 or less.

Our DiD estimator would be biased if the change in university enrolment between high school graduates aged 18 or less and their peers aged 19 or above systematically evolves differently across males and females. One way of testing this assumption is to carry out a pre-program test using a sample of individuals who finished high school in the years preceding the abolition of CMS. More precisely, using a sample of high school graduates who successfully completed their studies in 2001, the following DiD estimator can be computed:

(11) $\Delta_{2001}^{2}=\left(E_{M}^{\leq 18}-E_{M}^{\geq 19}\right)-\left(E_{F}^{\leq 18}-E_{F}^{\geq 19}\right)$

An adjusted double-difference for the 2001 sample of high school graduates can be computed by estimating an equation analogous to Equation (10). If in this equation the estimated DiD coefficient turns out not to be statistically significant, such a result would support the hypothesis that $\beta_{3}$ in Equation (10) identifies the causal effect of the abolition of CMS on university enrolment. If, however, in the 2001 sample the difference in university enrolment between high school graduates aged 18 or less and their peers age 19 or above is found to be higher among males than among females, then the DiD estimator in Equation (10) is likely to overstate the true effect of the abolition of CMS on university enrolment. Finally, a negative and statistically significant value of the adjusted double-difference estimator for the 2001 sample implies that the DiD coefficient in Equation (10) is likely to understate the true effect of the abolition of CMS on university enrolment.

By pooling the 2001 and 2004 samples of high school graduates it is possible to obtain a difference-in-difference-in-differences (DiDiD) or triple-difference estimator following the approach of Hamermesh and Trejo (2000) and Bansak and Rapahel (2001). We subtract the DiD estimator for the 2004 sample from the comparable DiD estimator for the 2001 sample.

(12) $\Delta^{3}=\Delta_{2004}^{2}-\Delta_{2001}^{2}$ 
To compute the DiDiD estimator within a regression framework, the following regression is estimated:

$$
E_{i}=\alpha+\beta_{0} X_{i}+\beta_{1} M_{i}+\beta_{2} T_{i}+\beta_{3} D_{i}+\beta_{4} T M_{i}+\beta_{5} D_{i} M_{i}+\beta_{6} D_{i} T_{i}+\beta_{7} D_{i} M_{i} T_{i}+\varepsilon_{i}
$$

where $D_{i}$ is dummy variable taking the value 1 if the high school graduate successfully completed his/her studies in 2004, and 0 otherwise. The coefficient $\beta_{7}$ represents the triple-difference estimator. It measures the extent to which in the 2004 sample the university enrolment gap between our two age-groups of male high school graduates, relative to the university enrolment gap between the two similar female groups, is statistically different from the comparable difference-in-differences in the 2001 sample. If the adjusted double-difference for the 2001 sample is equal to zero, then the triple difference estimator will reduce to the double-difference in Equation (10).

Our estimation strategy on the effect of the abolition of CMS on university enrolment is accompanied by one drawback which is common to the large majority of studies on the costs/benefits of military service. We assume that all male high school graduates born before $1^{\text {st }}$ January 1986 are subject to CMS. This is obviously not true because one would expect some of them to have been exempt for the reasons outlined in footnote 4. Such an issue, however, is unlikely to bias our estimates as long as the reasons behind the exemption, though possibly correlated with the university enrolment decision, are randomly distributed across males and females aged 18 or less when they finished high school.

Equations (10) and (13) can be estimated by OLS as this allows us to directly estimate the parameter of interest ${ }^{5}$. As pointed out by Angrist (2001), the problem of causal inference does not significantly differ between limited dependent variables and continuous outcomes. This means that if there are no covariates or the covariates are sparse and discrete, then linear models can be used to estimate models with limited

\footnotetext{
${ }^{5}$ As shown by Chunrong and Norton (2003), while in linear models the interpretation of the coefficient of the interaction between two variables is straightforward, this does not hold in non-linear models.
} 
dependent variables as well as models with other types of dependent variables. Berlinski and Galiani (2007) argue that institutional reform and policy experiments clearly fall within this framework since control variables are primarily added in an attempt to improve the efficiency of the estimates, but their omission is unlikely to significantly bias the estimates of the parameter of interest. Borjas (2003, 2004) uses OLS to estimate double and triple differences models where the dependent variable is dichotomous.

\section{Data}

The data for this study are taken from two waves (i.e. 2004 and 2007) of a national cross-sectional survey (Percorsi di Studio e di Lavoro dei Diplomati) carried out by the Italian National Statistical Institute (ISTAT). Each wave consists of a representative sample of high school graduates who are surveyed three years after completing their studies. Thus these data enable us to examine the post-high school decisions made by two cohorts of individuals who completed their studies in $2001^{6}$ and 2004. Although one of the possible destinations of these individuals is university enrolment, there are other possible trajectories. Some people may start to work immediately while others may become job seekers, and they can all change their mind after the initial choice. The survey contains individual information on previous educational attainment, parents' socio-economic status as well as a range of personal attributes.

In Italy all high school graduates gain the automatic right of entry to university, provided that they have successfully completed five years in high school ${ }^{7}$. The underlying idea behind this provision is to give to each high school graduate the opportunity of experimenting to see whether he/she is university material (Manski, 1989).

Our empirical analysis considers four different sets of characteristics that are likely to affect the decision to enrol at university. The first group consists of three proxies for the individual's academic ability. These indicators are: lower secondary school

\footnotetext{
${ }^{6}$ Earlier cohorts of high school graduates cannot be considered for the purpose of this study given that in 2001 the Italian university system embarked on a process of reform which led to the introduction of the " $3+2$ " model (for more details about this reform see Bratti et al., 2006)

${ }^{7}$ There are no admission standards, except for specialized disciplines such as medicine and architecture.
} 
(scuola media) final grade, high school final grade and a dummy variable recording whether the individual has failed and had to repeat at least one year at high school. The second set of factors includes school-related variables. We include indicators for the type of high school attended by the individual and a dummy variable recording whether this high school was public or private. The third group of variables comprises individual personal attributes such as gender, age and area of residence ${ }^{8}$. Finally, we include family background characteristics such as parents' highest educational attainment and father's occupation ${ }^{9}$.

Following the approach of Cappellari (2004) and Di Pietro and Cutillo (2008), we eliminate from the final sample those individuals who graduated from those high schools mainly designed to train primary school teachers (scuole magistrali). These schools have a different structure relative to the other types of high schools. Additionally, we exclude from the final sample high school graduates living abroad and those who, though they enrolled at university, did not do so immediately after completing their studies. After deleting observations with missing variables of interest, we are left with 20,846 and 16,959 high school graduates in the 2004 and 2001 samples, respectively.

Table 1 provides some descriptive statistics for all the variables used in this study. Although in Italy the large majority of people successfully complete high school at the age of 19 or above, some manage to do it at the age of 18 (or less in very exceptional cases). These are individuals who, at the age of 5, attended a special course (primina), upon successful completion of which they were allowed to skip the first year of primary school. This means that at the age of 6 , when most children begin primary school, they were admitted to the second year of primary school ${ }^{10}$.

\section{Insert Table 1 about here}

\footnotetext{
${ }^{8}$ Four geographical areas are considered: North-East, North-West, South and Centre. Unfortunately, we are unable to define areas of residence at a more disaggregated level (i.e. region) given that this information is unavailable. The inclusion of dummies for area of residence allows us to control for labour market conditions across the geographical areas.

${ }_{9}^{9}$ Given the low direct cost of university education in Italy (compared to other countries such as, for instance, the US), tuition fees are unlikely to exert an influence on the enrolment decision even for individuals from less advantaged backgrounds. Previous studies (see for, instance, Di Pietro and Cutillo, 2006) on the determinants of university enrolment in Italy have not considered the impact of this factor.

${ }^{10}$ Typically parents can freely decide to make their child attend primina. The child has the right to enrol on the second year of primary school as long as he/she passes a final exam.
} 
From Table 1 it emerges that in both the 2001 and 2004 samples university enrolment rate is significantly higher among individuals who finished high school at the age of 18 or less relative to their older peers. For instance, in the 2004 sample the proportion of people who enrolled at university immediately after successfully completing high school is $80 \%$ among the former group, compared to $57 \%$ among latter group. This is also due to the fact that people who finished high school at the age of 18 or less typically show higher academic ability and are more likely to come from a more privileged family background than their older peers. This finding is in line with our expectations given that well-educated parents have high educational expectations for their children and hence they may want them to start school earlier.

\section{Empirical results}

The results reported in the first half of Table 2 present the double-difference estimates for the 2004 sample, which emerge from a very basic university enrolment specification. The DiD coefficient is statistically significant at all conventional levels and has a positive sign. Our empirical results show that after the abolition of CMS the change in the probability of enrolling at university between our two age-groups of high school graduates was 15 percentage points higher across males relative to females.

\section{Insert Table 2 about here}

A number of personal, family background and school-related characteristics are added to our basic university enrolment equation. The result for this new specification is depicted in the second half of Table 2. The empirical findings are generally consistent with previous research. Attending a general high school (liceo), performing well at high school, not repeating a high school year, being female, studying at a public high school $^{11}$, having well-educated parents all result in a higher probability of enrolling at university. Moving to the variable of primary interest in this study, one may note that the DiD coefficient is still statistically significant at the 1 percent level. Nevertheless, its value is smaller than the corresponding one in the first half of Table 2. More precisely, our results imply that controlling for observable individual characteristics

\footnotetext{
${ }^{11}$ Several studies (see, for instance, Bertola and Checchi, 2002) suggest that in Italy private schools play a remedial role. They tend to attract less talented students from wealthy backgrounds.
} 
removes approximately one-third of the estimated difference-in-differences shown in the first half of Table 2 .

To test whether the results depicted in Table 2 are robust, we check the sensitivity of our estimates to our definition of university enrolment. Hence we include in the final sample those high school graduates who enrolled at university, but instead of doing it immediately after finishing their studies, they did it two or three years later. The increase in sample size is, however, quite modest given that in Italy the majority of high school graduates enrol at university straight after completing their studies. Estimates based on this larger sample are depicted in Table 3. Not only in both model specifications the DiD coefficients are still positive and statistically significant at the 1 percent level, but also their values are relatively close to the corresponding values of the DiD coefficients depicted in Table 2. In light of these results, it is possible to conclude that our estimates are not sensitive to changes in the definition of university enrolment

\section{Insert Table 3 about here}

Our DiD estimates seem to suggest that the abolition of CMS is actually driving the higher university enrolment growth experienced by male high school graduates aged 18 or less compared to their peers aged 19 or above, relative to the growth in university enrolment between similar female groups. This finding, however, relies on the identification assumption according to which in the absence of the abolition of CMS the increase in university enrolment of the high school graduates aged 18 or less relative to their older peers would have been the same across males and females. In order to test this hypothesis, two different tests are carried out. First, following the approach of Duflo (2001), we perform a control experiment. An implication of the identification assumption is that, since in 2004 males who successfully completed high school at the age of 19 or above were not affected by the military reform, the increase in university enrolment between two cohorts in this age-group should not be systematically different across males and females. Hence we restrict our 2004 sample to those individuals who successfully completed high school at the age of 19 or above and then we split them in two cohorts: a cohort of individuals who finished high school at the age of 19 and a cohort of individuals who were older than 19 years when 
they finished high school. To compute the new difference-in-differences, we estimate the following equation:

(14) $E_{i}=\alpha+\beta_{0} X_{i}+\beta_{1} M_{i}+\beta_{8} K_{i}+\beta_{9} K_{i} M_{i}+\varepsilon_{i}$

where $\mathrm{K}$ is a dummy variable taking the value 1 if the individual finished high school when he/she was 19 years old, and 0 otherwise

The estimates from the less parsimonious specification, which are depicted in the second half of Table 4, suggest that assigning a causal interpretation to the DiD coefficient shown in the second half of Table 2 is suspect: also the change in the probability of enrolling at university enrolment between high school graduates aged 19 and their peers older than 19 years is higher across males than across females after the abolition of CMS.

\section{Insert Table 4 about here}

A more convincing test for the validity of the identification assumption is represented by a pre-program test. The idea is to check whether in the years preceding the implementation of the military reform the university enrolment gap between our two age-groups of high school graduates already exhibited a different trend across males and females. Hence we perform a pre-program test using a sample of people who finished high school in 2001. The estimates reported in Table 5 suggest that in the period before the abolition of CMS the trend in relative high school graduates aged 18 or less/ high school graduates aged 19 or above university enrolment was already different across males and females. During such a period this trend was flatter across females relative to males. More specifically, in the less parsimonious specification the difference in the probability of enrolling at university between our two age-groups of high school graduates was 5.4 percentage points higher across males than across females. This finding confirms the inappropriateness of our $\mathrm{DiD}$ identification assumption. In light of the evidence reported in Table 5, the DiD estimates depicted in Table 2 are likely to overestimate the effect of the suppression of CMS on university enrolment.

Insert Table 5 about here 
Next we need to adjust the DiD estimates reported in Table 2 in order to consider the differential university enrolment trend between our two age-groups across males and females in the years preceding the implementation of the military reform. As outlined in Section 4, one way to account for this differential trend is to employ the tripledifference model. This model attempts to subtract the bias revealed through the preprogram test from the effect of the abolition of CMS estimated using the DiD model. Specifically, it tests whether in the 2004 sample the growth in university enrolment shown by male high school graduates aged 18 or less compared to their peers aged 19 or above, relative to the comparable growth between similar female groups, is statistically different from the corresponding difference-in-differences in the 2001 sample. These triple-difference estimates are reported in Table 6. Whilst in our very basic specification the DiDiD coefficient has a positive sign and is statistically significant at the 5 percent level, in the full control specification it retains the positive sign but loses its statistical significance. Consequently, there appears to be no compelling evidence indicating that in the 2004 sample the gender difference in the probability of enrolling at university between high school graduates aged 18 or less and their older peers has actually been driven by the abolition of CMS. Our results suggest that, not only this gender difference already existed before the abolition of CMS, but also that the difference between these two differences is not statistically significant.

\section{Insert Table 6 about here}

Although the DiDiD estimates reported in Table 6 show that the abolition of CMS has no significant overall effect on university enrolment, it is still possible that the effect differs across individuals with different characteristics. As outlined in the theoretical framework set up in Section 2, holding wages for university and high school graduates constant, the suppression of CMS may encourage university participation among individuals with lower discount rates, but at the same time it may discourage university participation among those with higher discount rates. In the returns to education literature it is generally assumed (see, for instance, Card, 1994) that people from more advantaged family backgrounds (i.e. higher-income people) tend to have lower discount rates than those from less advantaged family backgrounds. Hence, to test whether the 2004 military reform is associated with any heterogeneous effects, we 
estimate our triple-difference model for individuals from more and less advantaged family backgrounds, separately. Father's occupation is used as a proxy for family background. While the first half of Table 7 reports the DiDiD estimates for individuals whose father has either a high-level occupation or a medium-level occupation, the second half of Table 7 presents the corresponding estimates for those whose father has either a low-level occupation or other/unknown occupations ${ }^{12}$.

\section{Insert Table 7 about here}

Table 7 shows some evidence of heterogeneous effects. While in the first half of Table 7 the DiDiD coefficient is statistically significant at the 10 percent level and has a positive sign, in the second half of Table 7 the corresponding coefficient is statistically significant at the 5 percent level but has a negative sign. Thus these results would seem to support the hypothesis that, while the abolition of CMS increased university participation among individuals from more privileged family backgrounds, it had a negative impact on the enrolment of those from less privileged family backgrounds. Although male individuals with higher discount rates choose lower levels of education, the presence of CMS, because of its associated costs, could have diverted them towards a longer investment in schooling. On the other hand, the longer payoff period associated with investment in university education, which is triggered by the abolition of CMS, could encourage male high school graduates with a stronger taste for schooling (or lower discount rates) to continue studying.

\section{Conclusions}

Given that several countries throughout the world have already abolished or are considering the abolition of CMS, understanding the consequences of this measure is of increased concern. In this paper we have attempted to analyse the effect of the suppression of CMS on the decision to enrol at university among Italian male high school graduates. Studying the factors influencing the transition from secondary to tertiary education is very important as investing in higher education is expected to bring significant benefits not only to individuals but also to society as a whole.

\footnotetext{
12 The inclusion of geographical area dummies in the specification allows us to control for differences in the wage differential between university and high school graduates living in the same area.
} 
The abolition of CMS may have conflicting effects on the university enrolment decision of male high school graduates. On the one hand, it may discourage them from attending university as they no longer need to continue studying in order to avoid military service. This argument hinges on the idea that young men typically perceive the military service to be associated with several costs and hence they want to postpone it as long as they can. On the other hand, however, high school graduates may be more willing to invest in university education as the dismissal of CMS implies a longer payoff period for this investment.

In Italy in 2004 those male individuals who successfully completed high school at the age of 18 or less were not at risk of service. Our identification strategy is to compare their university enrolment decision with that of their older peers, relative to the corresponding difference between similar female groups. This approach allows us to account for unobserved age-group specific effects and common macro-effects in addition to observable characteristics. Double-difference estimates show that the difference in university enrolment between these two age-groups of high school graduates is higher across males relative to females. However, a pre-program test reveals that in the years preceding the abolition of CMS the university enrolment gap between high school graduates aged 18 or less and their older peers was already higher across males than across females. In light of this result, we compare the gender difference in university enrolment between these two groups during the period after the abolition of CMS with the corresponding one during the period before the abolition of CMS. As the difference between these two differences is not statistically different from zero, our estimates suggest that the abolition of CMS had no statistically significant effect on university participation rate.

Although the triple-difference estimates suggest that the abolition of CMS has no significant overall effect on university enrolment, we find some evidence of heterogeneous effects. While this measure seems to increase university participation among individuals from more advantaged backgrounds, it appears to have a detrimental effect on the enrolment of those from less advantaged backgrounds. These findings may have considerable policy implications. Given that Italy is characterised by great inequality in access to university education (Di Pietro, 2008), there is the risk that the abolition of CMS may further exacerbate this situation. 


\section{References}

Angrist, J.D. (1990) "Lifetime earnings and the Vietnam era draft lottery: evidence from social security administrative records”, American Economic Review, 80(3), 313336.

Angrist, J.D. (2001) "Estimation of limited-dependent variable models with binary endogenous regressors: simple strategies for empirical practice”, Journal of Business Economics and Statistics, 19 (1), 2-16.

Angrist, J.D. and Krueger, A.B. (1989) Why do World War II veterans earn more than nonveterans?, Working Paper 2991, National Bureau of Economic Research.

Angrist, J.D. and Krueger, A.B. (1992) Estimating the payoff to schooling using the Vietnam-era draft lottery, Working Paper 4067, National Bureau of Economic Research

Bansak, C. and Raphael, S. (2001) "Immigration reform and the earnings of Latino workers: Do employers sanctions cause discrimination?”, Industrial and Labor Relations Review, 54(2), 275-295.

Bauer, T.K., Bender, S. and Schmidt, C.M. (2004) Evaluating the labor market effects of compulsory military service: A regression-discontinuity approach, unpublished manuscript, IZA, Bonn.

Baum, B.S., and Payea, K. (2004) Education pays 2004: The benefits of higher education for individuals and society, The College Board.

Becker, G.S. (1964) Human Capital. New York: Columbia University Press.

Berlinski S. and Galiani, S. (2007) "The effect of a large expansion of pre-primary school facilities on preschool attendance and maternal employment", Labour Economics, 14 (3), 665-680.

Bertola, G. and Checchi, D. (2002). Sorting and private education in Italy, Center for Economic Policy Research, Discussion Paper, No. 3198.

Borjas, G.L. (2004) "Food insecurity and public assistance”, Journal of Public Economics, 88 (7-8), 1421-1443.

Borjas, G.L. (2003) "Welfare reform, labour supply, and health insurance in immigrant population”, Journal of Health Economics, 22 (6), 933-958.

Bratti, M., Broccolini, C. and Staffolani, S. (2006) Is '3+2' Equal to 4? University Reform and Student Academic Performance in Italy, Università Politecnica delle Marche, Dipartimento di Economia, Working Paper, n. 251.

Buonanno, P. (2006) Long-term effects of conscription: Lessons from the UK, Working Paper 2006/4, Dipartimento di Scienze Economiche "Hyman P. Minsky”, Università degli studi di Bergamo 
Cappellari, L. (2004) High school types, academic performance and early labour market outcomes, IZA Discussion paper no. 1048.

Card, D. and Lemieux, T. (2001) "Going to college to avoid the draft: the unintended legacy of the Vietnam war”, American Economic Review, 91(2), 97-102.

Card, D. (1994) Earnings, schooling and ability revisited, Working Paper No. 4832, National Bureau of Economic Research.

Chunrong, A. and Norton, E. (2003) "Interaction terms in logit and probit models", Economics Letters, 80 (1), 123-129.

Cipollone, P. and Rosolia, A. (2007) "Social interactions in high school: Lessons from an earthquake”, American Economic Review, 97(3), 948-965.

Di Pietro, G. (2008) "Changes in the extent of inequality in access to university education in Italy”, Rivista di Politica Economica, 1, 175-213.

Di Pietro, G. and Cutillo, A. (2008) "Degree flexibility and university drop-out: the Italian experience”, Economics of Education Review, 27(5), 546-555.

Di Pietro, G. and Cutillo, A (2006) "Does attending a catholic school make a difference? Evidence from Italy”, Bulletin of Economic Research, 58 (3), 193-234.

Duflo, E. (2001) Schooling and labor market consequences of school construction in Indonesia: Evidence from am unusual policy experiment, American Economic Review, 91(4), 795-813

Hamermesh, D.S. and Trejo S.J. (2000) "The demand for hours of labor: Direct evidence from California”, Review of Economics and Statistics, 82(1), 38-47.

Imbens, G.and van der Klaauw, W. (1995) "Evaluating the cost of conscription in the Netherlands”, Journal of Business and Economic Statistics, 13(2), 207-215

Manski, C.F. (1989) "Schooling as experimentation: A reappraisal of the postsecondary dropout phenomenon”, Economics of Education Review, 8(4), 305-312.

Maurin, E. and Xenogiani, T. (2007) "Demand for education and labor market outcomes: Lessons from the abolition of compulsory conscription in France", Journal of Human Resources, 42(4), 795-819

Neuman, S. and Weiss, A. (1995) "On the effects of schooling vintage on experienceearnings profiles: Theory and evidence", European Economic Review, 39(5), 943-955. 
Table 1. Mean and standard deviation (in brackets) of variables

\begin{tabular}{|c|c|c|c|c|}
\hline & \multicolumn{2}{|c|}{2004 high school graduates } & \multicolumn{2}{|c|}{2001 high school graduates } \\
\hline & $\begin{array}{l}\text { Aged } 18 \text { or } \\
\text { less }\end{array}$ & Aged 19 or more & $\begin{array}{l}\text { Aged } 18 \text { or } \\
\text { less }\end{array}$ & Aged 19 or more \\
\hline Enrolled at university $=1$, otherwise $=0$ & $0.80(0.40)$ & $0.57(0.49)$ & $0.82(0.38)$ & $0.56(0.50)$ \\
\hline Male $=1$, otherwise 0 & $0.47(0.50)$ & $0.52(0.50)$ & $0.41(0.49)$ & $0.53(0.50)$ \\
\hline \multicolumn{5}{|l|}{ Area of residence } \\
\hline North-West $=1$, otherwise $=0$ & $0.08(0.27)$ & $0.22(0.41)$ & $0.05(0.22)$ & $0.23(0.42)$ \\
\hline North-East $=1$, otherwise $=0$ & $0.04(0.20)$ & $0.17(0.37)$ & $0.03(0.16)$ & $0.17(0.38)$ \\
\hline Centre $=1$, otherwise $=0$ & $0.11(0.31)$ & $0.20(0.40)$ & $0.08(0.27)$ & $0.21(0.41)$ \\
\hline South $=1$, otherwise $=0$ & $0.77(0.42)$ & $0.41(0.49)$ & $0.84(0.36)$ & $0.39(0.49)$ \\
\hline \multicolumn{5}{|l|}{ Academic ability } \\
\hline Failed high school year $=1$, otherwise $=0$ & $0.01(0.10)$ & $0.20(0.40)$ & $0.01(0.11)$ & $0.25(0.43)$ \\
\hline \multicolumn{5}{|l|}{ Performance at lower secondary school } \\
\hline Pass $=1$, otherwise $=0$ & $0.12(0.33)$ & $0.27(0.44)$ & $0.08(0.28)$ & $0.26(0.44)$ \\
\hline Good $=1$, otherwise $=0$ & $0.25(0.43)$ & $0.30(0.46)$ & $0.20(0.40)$ & $0.30(0.46)$ \\
\hline Very good $=1$, otherwise $=0$ & $0.27(0.44)$ & $0.22(0.42)$ & $0.29(0.45)$ & $0.21(0.41)$ \\
\hline Excellent $=1$, otherwise $=0$ & $0.36(0.48)$ & $0.21(0.40)$ & $0.43(0.50)$ & $0.23(0.42)$ \\
\hline \multicolumn{5}{|l|}{ High school degree classification } \\
\hline $60-69=1$, otherwise $=0$ & $0.17(0.38)$ & $0.32(0.46)$ & $0.21(0.41)$ & $0.35(0.48)$ \\
\hline $70-79=1$, otherwise $=0$ & $0.22(0.42)$ & $0.26(0.440$ & $0.18(0.38)$ & $0.27(0.44)$ \\
\hline $80-89=1$, otherwise $=0$ & $0.18(0.38)$ & $0.19(0.39)$ & $0.24(0.43)$ & $0.18(0.38)$ \\
\hline $90-100=1$, otherwise $=0$ & $0.43(0.49)$ & $0.24(0.43)$ & $0.37(0.48)$ & $0.20(0.40)$ \\
\hline \multicolumn{5}{|l|}{ School-related characteristics } \\
\hline Private high school $=1$, otherwise $=0$ & $0.08(0.27)$ & $0.07(0.25)$ & $0.04(0.20)$ & $0.04(0.20)$ \\
\hline \multicolumn{5}{|l|}{ Type of high school } \\
\hline General $=1$, otherwise $=0$ & $0.58(0.49)$ & $0.32(0.47)$ & $0.66(0.47)$ & $0.33(0.47)$ \\
\hline Professional $=1$, otherwise $=0$ & $0.07(0.25)$ & $0.20(0.40)$ & $0.04(0.20)$ & $0.18(0.38)$ \\
\hline Technical $=1$, otherwise $=0$ & $0.29(0.45)$ & $0.45(0.50)$ & $0.22(0.42)$ & $0.46(0.50)$ \\
\hline Artistic $==1$, , otherwise $=0$ & $0.07(0.25)$ & $0.04(0.19)$ & $0.07(0.26)$ & $0.03(0.18)$ \\
\hline \multicolumn{5}{|l|}{ Family background } \\
\hline \multicolumn{5}{|l|}{ Father's education } \\
\hline Primary school or less $=1$, otherwise $=0$ & $0.06(0.23)$ & $0.13(0.34)$ & $0.06(0.23)$ & $0.14(0.35)$ \\
\hline Lower secondary school $=1$, otherwise $=0$ & $0.21(0.41)$ & $0.38(0.49)$ & $0.21(0.41)$ & $0.39(0.49)$ \\
\hline High school $=1$, otherwise $=0$ & $0.43(0.49)$ & $0.39(0.49)$ & $0.41(0.49)$ & $0.36(0.48)$ \\
\hline University $=1$, otherwise $=0$ & $0.31(0.46)$ & $0.10(0.30)$ & $0.32(0.47)$ & $0.11(0.31)$ \\
\hline \multicolumn{5}{|l|}{ Mother's education } \\
\hline Primary school or less $=1$, otherwise $=0$ & $0.05(0.23)$ & $0.14(0.34)$ & $0.08(0.27)$ & $0.17(0.37)$ \\
\hline Lower secondary school $=1$, otherwise $=0$ & $0.22(0.41)$ & $0.39(0.49)$ & $0.22(0.41)$ & $0.40(0.49)$ \\
\hline High school $=1$, otherwise $=0$ & $0.43(0.49)$ & $0.39(0.49)$ & $0.41(0.49)$ & $0.35(0.48)$ \\
\hline University $=1$, otherwise $=0$ & $0.30(0.46)$ & $0.09(0.28)$ & $0.30(0.46)$ & $0.09(0.28)$ \\
\hline \multicolumn{5}{|l|}{ Father's occupation } \\
\hline High-level $=1$, otherwise $=0$ & $0.36(0.48)$ & $0.17(0.38)$ & $0.39(0.49)$ & $0.20(0.40)$ \\
\hline Medium-level $=1$, otherwise $=0$ & $0.43(0.49)$ & $0.39(0.49)$ & $0.39(0.49)$ & $0.38(0.49)$ \\
\hline Low-level $=1$, otherwise $=0$ & $0.18(0.38)$ & $0.42(0.49)$ & $0.20(0.40)$ & $0.39(0.49)$ \\
\hline Other-unknown $=1$, otherwise $=0$ & $0.03(0.18)$ & $0.02(0.15)$ & $0.02(0.15)$ & $0.03(0.16)$ \\
\hline Number of observations & 783 & 20,063 & 591 & 16,368 \\
\hline
\end{tabular}

Survey weights have been used 
Table 2. Effect of the abolition of military conscription on university enrolment: double-difference estimates

\begin{tabular}{|c|c|c|c|c|}
\hline & Coefficient & Standard Error & Coefficient & Standard Error \\
\hline Constant & $0.640 *$ & 0.005 & $1.141^{*}$ & 0.012 \\
\hline $\begin{array}{l}\text { Aged } 18 \text { or less when finished } \\
\text { high school=1, otherwise } 0\end{array}$ & $0.143^{*}$ & 0.020 & $-0.047 * *$ & 0.016 \\
\hline Male $=1$, otherwise 0 & $-0.126^{*}$ & 0.007 & $-0.019 *$ & 0.006 \\
\hline $\begin{array}{l}\text { Aged } 18 \text { or less when finished } \\
\text { high school }=1 \text {, otherwise } 0 * \\
\text { Male }=1 \text {, otherwise } 0\end{array}$ & $0.150 *$ & 0.029 & $0.095 *$ & 0.023 \\
\hline \multicolumn{5}{|c|}{ Area of residence -Reference category is South } \\
\hline North-West $=1$, otherwise $=0$ & & & $0.027 *$ & 0.007 \\
\hline North-East $=1$, otherwise $=0$ & & & -0.008 & 0.008 \\
\hline Centre $=1$, otherwise $=0$ & & & 0.003 & 0.007 \\
\hline $\begin{array}{l}\text { Failed high school year }=1, \\
\text { otherwise }=0\end{array}$ & & & $-0.069 *$ & 0.007 \\
\hline \multicolumn{5}{|c|}{ High school degree classification- Reference category is $90-100$} \\
\hline $60-69=1$, otherwise $=0$ & & & $-0.250 *$ & 0.008 \\
\hline $70-79=1$, otherwise $=0$ & & & $-0.146^{*}$ & 0.008 \\
\hline $80-89=1$, otherwise $=0$ & & & $-0.075^{*}$ & 0.008 \\
\hline \multicolumn{5}{|c|}{ Performance at lower secondary school- Reference category is excellent } \\
\hline Pass $=1$, otherwise $=0$ & & & $-0.126 *$ & 0.010 \\
\hline Good $=1$, otherwise $=0$ & & & $-0.039 *$ & 0.009 \\
\hline Very good $=1$, otherwise $=0$ & & & $0.015^{* * *}$ & 0.009 \\
\hline $\begin{array}{l}\text { Private high school }=1 \text {, } \\
\text { otherwise }=0\end{array}$ & & & $-0.082 *$ & 0.011 \\
\hline \multicolumn{5}{|c|}{ Type of high school- Reference category is General } \\
\hline Professional $=1$, otherwise $=0$ & & & $-0.495^{*}$ & 0.010 \\
\hline Technical $=1$, otherwise $=0$ & & & $-0.305^{*}$ & 0.007 \\
\hline Artistic $==1$, , otherwise $=0$ & & & -0.428 & 0.015 \\
\hline \multicolumn{5}{|c|}{ Father's education- Reference category is University } \\
\hline $\begin{array}{l}\text { Primary school or less }=1 \text {, } \\
\text { otherwise }=0\end{array}$ & & & $-0.108 *$ & 0.015 \\
\hline $\begin{array}{l}\text { Lower secondary school=1, } \\
\text { otherwise }=0\end{array}$ & & & $-0.065 *$ & 0.012 \\
\hline High school $=1$, otherwise $=0$ & & & $-0.021 * * *$ & 0.011 \\
\hline \multicolumn{5}{|c|}{ Mother's education- Reference category is University } \\
\hline $\begin{array}{l}\text { Primary school or less }=1, \\
\text { otherwise }=0\end{array}$ & & & $-0.120 *$ & 0.014 \\
\hline $\begin{array}{l}\text { Lower secondary school=1, } \\
\text { otherwise }=0\end{array}$ & & & $-0.071 *$ & 0.012 \\
\hline High school $=1$, otherwise $=0$ & & & -0.003 & 0.010 \\
\hline \multicolumn{5}{|c|}{ Father's occupation- Reference category is High-level } \\
\hline Medium-level=1, otherwise $=0$ & & & -0.010 & 0.009 \\
\hline Low-level $=1$, otherwise $=0$ & & & $-0.054 *$ & 0.009 \\
\hline Other-unknown $=1$, otherwise $=0$ & & & $-0.096^{*}$ & 0.019 \\
\hline R-squared & 0.027 & & 0.408 & \\
\hline Number of observations & 20,846 & & 20,846 & \\
\hline
\end{tabular}

* denotes statistically significant at the $1 \%$ level

** denotes statistically significant at the $5 \%$ level

*** denotes statistically significant at the $10 \%$ level

Survey weights are used in the regression analysis 
Table 3. Effect of the abolition of military conscription on university enrolment: double-difference estimates - different university enrolment definition

\begin{tabular}{|c|c|c|c|c|}
\hline & Coefficient & Standard Error & Coefficient & Standard Error \\
\hline Constant & $0.671^{*}$ & 0.005 & $1.132 *$ & 0.011 \\
\hline $\begin{array}{l}\text { Aged } 18 \text { or less when finished } \\
\text { high school=1, otherwise } 0\end{array}$ & $0.143 *$ & 0.018 & $-0.032 * *$ & 0.015 \\
\hline Male $=1$, otherwise 0 & $-0.113^{*}$ & 0.007 & $-0.018 *$ & 0.006 \\
\hline $\begin{array}{l}\text { Aged } 18 \text { or less when finished } \\
\text { high school }=1 \text {, otherwise } 0 * \\
\text { Male }=1 \text {, otherwise } 0\end{array}$ & $0.131 *$ & 0.027 & $0.077 *$ & 0.022 \\
\hline \multicolumn{5}{|c|}{ Area of residence-Reference category is South } \\
\hline North-West $=1$, otherwise $=0$ & & & $0.024^{*}$ & 0.007 \\
\hline North-East $=1$, otherwise $=0$ & & & -0.010 & 0.008 \\
\hline Centre $=1$, otherwise $=0$ & & & 0.005 & 0.007 \\
\hline $\begin{array}{l}\text { Failed high school year=1, } \\
\text { otherwise }=0\end{array}$ & & & $-0.045^{*}$ & 0.007 \\
\hline \multicolumn{5}{|c|}{ High school degree classification- Reference category is 90-100 } \\
\hline $60-69=1$, otherwise $=0$ & & & $-0.237 *$ & 0.008 \\
\hline 70-79=1, otherwise $=0$ & & & $-0.132 *$ & 0.008 \\
\hline $80-89=1$, otherwise $=0$ & & & $-0.068 *$ & 0.008 \\
\hline \multicolumn{5}{|c|}{ Performance at lower secondary school-Reference category is excellent } \\
\hline Pass $=1$, otherwise $=0$ & & & $-0.128 *$ & 0.010 \\
\hline Good $=1$, otherwise $=0$ & & & $-0.027 *$ & 0.009 \\
\hline Very good $=1$, otherwise $=0$ & & & $0.019 * *$ & 0.008 \\
\hline $\begin{array}{l}\text { Private high school=1, } \\
\text { otherwise }=0\end{array}$ & & & $-0.081 *$ & 0.010 \\
\hline \multicolumn{5}{|c|}{ Type of high school- Reference category is General } \\
\hline Professional $=1$, otherwise $=0$ & & & $-0.463 *$ & 0.009 \\
\hline Technical $=1$, otherwise $=0$ & & & $-0.277^{*}$ & 0.007 \\
\hline Artistic $==1$, , otherwise $=0$ & & & $-0.381^{*}$ & 0.014 \\
\hline \multicolumn{5}{|c|}{ Father's education- Reference category is University } \\
\hline $\begin{array}{l}\text { Primary school or less }=1 \text {, } \\
\text { otherwise }=0\end{array}$ & & & $-0.100 *$ & 0.014 \\
\hline $\begin{array}{l}\text { Lower secondary school=1, } \\
\text { otherwise }=0\end{array}$ & & & $-0.065 *$ & 0.012 \\
\hline High school $=1$, otherwise $=0$ & & & $-0.023 * *$ & 0.011 \\
\hline \multicolumn{5}{|c|}{ Mother's education- Reference category is University } \\
\hline $\begin{array}{l}\text { Primary school or less }=1, \\
\text { otherwise }=0\end{array}$ & & & $-0.109 *$ & 0.013 \\
\hline $\begin{array}{l}\text { Lower secondary school=1, } \\
\text { otherwise }=0\end{array}$ & & & $-0.068 *$ & 0.011 \\
\hline High school $=1$, otherwise $=0$ & & & 0.0002 & 0.010 \\
\hline \multicolumn{5}{|c|}{ Father's occupation- Reference category is High-level } \\
\hline Medium-level $=1$, otherwise $=0$ & & & -0.006 & 0.008 \\
\hline Low-level $=1$, otherwise $=0$ & & & $-0.049 *$ & 0.009 \\
\hline Other-unknown $=1$, otherwise $=0$ & & & $-0.073^{*}$ & 0.018 \\
\hline R-squared & 0.023 & & 0.360 & \\
\hline Number of observations & 22,859 & & 22,859 & \\
\hline
\end{tabular}

* denotes statistically significant at the $1 \%$ level

** denotes statistically significant at the $5 \%$ level

*** denotes statistically significant at the $10 \%$ level

Survey weights are used in the regression analysis 
Table 4 Effect of the abolition of military conscription on university enrolment: double-difference estimates - control experiment

\begin{tabular}{|c|c|c|c|c|}
\hline & Coefficient & Standard Error & Coefficient & Standard Error \\
\hline Constant & $0.358^{*}$ & 0.104 & $1.026^{*}$ & 0.016 \\
\hline $\begin{array}{l}\text { Aged } 19 \text { when finished high } \\
\text { school=1, otherwise } 0\end{array}$ & $0.356 *$ & 0.012 & $0.115^{*}$ & 0.011 \\
\hline Male $=1$, otherwise 0 & $-0.078 *$ & 0.013 & $-0.065 *$ & 0.011 \\
\hline $\begin{array}{l}\text { Aged } 19 \text { when finished high } \\
\text { school=1, otherwise } 0 * \text { Male }=1 \text {, } \\
\text { otherwise } 0\end{array}$ & 0.009 & 0.015 & $0.069 *$ & 0.012 \\
\hline \multicolumn{5}{|c|}{ Area of residence-Reference category is South } \\
\hline North-West $=1$, otherwise $=0$ & & & $0.028^{*}$ & 0.007 \\
\hline North-East $=1$, otherwise $=0$ & & & -0.007 & 0.008 \\
\hline Centre $=1$, otherwise $=0$ & & & -0.002 & 0.007 \\
\hline $\begin{array}{l}\text { Failed high school year }=1 \text {, } \\
\text { otherwise }=0\end{array}$ & & & $0.048 *$ & 0.010 \\
\hline \multicolumn{5}{|c|}{ High school degree classification- Reference category is $90-100$} \\
\hline $60-69=1$, otherwise $=0$ & & & $-0.249 *$ & 0.009 \\
\hline $70-79=1$, otherwise $=0$ & & & $-0.145^{*}$ & 0.008 \\
\hline $80-89=1$, otherwise $=0$ & & & $-0.081^{*}$ & 0.009 \\
\hline \multicolumn{5}{|c|}{ Performance at lower secondary school- Reference category is excellent } \\
\hline Pass $=1$, otherwise $=0$ & & & $-0.110 *$ & 0.011 \\
\hline Good $=1$, otherwise $=0$ & & & $-0.041 *$ & 0.009 \\
\hline Very good $=1$, otherwise $=0$ & & & 0.010 & 0.009 \\
\hline $\begin{array}{l}\text { Private high school=1, } \\
\text { otherwise }=0\end{array}$ & & & $-0.062 *$ & 0.011 \\
\hline \multicolumn{5}{|c|}{ Type of high school- Reference category is General } \\
\hline Professional $=1$, otherwise $=0$ & & & $-0.487 *$ & 0.010 \\
\hline Technical=1, otherwise $=0$ & & & $-0.300^{*}$ & 0.007 \\
\hline Artistic $==1$, , otherwise $=0$ & & & $-0.411 *$ & 0.016 \\
\hline \multicolumn{5}{|c|}{ Father's education- Reference category is University } \\
\hline $\begin{array}{l}\text { Primary school or less }=1 \text {, } \\
\text { otherwise }=0\end{array}$ & & & $-0.101 *$ & 0.015 \\
\hline $\begin{array}{l}\text { Lower secondary school=1, } \\
\text { otherwise }=0\end{array}$ & & & $-0.069 *$ & 0.013 \\
\hline High school $=1$, otherwise $=0$ & & & -0.016 & 0.012 \\
\hline \multicolumn{5}{|c|}{ Mother's education- Reference category is University } \\
\hline $\begin{array}{l}\text { Primary school or less }=1 \text {, } \\
\text { otherwise }=0\end{array}$ & & & $-0.104^{*}$ & 0.014 \\
\hline $\begin{array}{l}\text { Lower secondary school=1, } \\
\text { otherwise }=0\end{array}$ & & & $-0.070 *$ & 0.012 \\
\hline High school $=1$, otherwise $=0$ & & & -0.011 & 0.011 \\
\hline \multicolumn{5}{|c|}{ Father's occupation- Reference category is High-level } \\
\hline Medium-level $=1$, otherwise $=0$ & & & -0.010 & 0.009 \\
\hline Low-level $=1$, otherwise $=0$ & & & $-0.051^{*}$ & 0.009 \\
\hline Other-unknown $=1$, otherwise $=0$ & & & $-0.084^{*}$ & 0.019 \\
\hline R-squared & 0.122 & & 0.413 & \\
\hline Number of observations & 20,063 & & 20,063 & \\
\hline
\end{tabular}

* denotes statistically significant at the $1 \%$ level

** denotes statistically significant at the $5 \%$ level

*** denotes statistically significant at the $10 \%$ level

Survey weights are used in the regression analysis 
Table 5. Effect of the abolition of military conscription on university enrolment: double-difference estimates - pre-program test

\begin{tabular}{|c|c|c|c|c|}
\hline & Coefficient & Standard Error & Coefficient & Standard Error \\
\hline Constant & $0.607 *$ & 0.006 & $1.144^{*}$ & 0.013 \\
\hline $\begin{array}{l}\text { Aged } 18 \text { or less when finished } \\
\text { high school=1, otherwise } 0\end{array}$ & $0.225 *$ & 0.021 & $-0.036 * *$ & 0.016 \\
\hline Male $=1$, otherwise 0 & $-0.087 *$ & 0.008 & $0.012 * *$ & 0.006 \\
\hline $\begin{array}{l}\text { Aged } 18 \text { or less when finished } \\
\text { high school=1, otherwise } 0 * \\
\text { Male }=1 \text {, otherwise } 0\end{array}$ & $0.062 * * *$ & 0.006 & $0.054^{* *}$ & 0.024 \\
\hline \multicolumn{5}{|c|}{ Area of residence -Reference category is South } \\
\hline North-West=1, otherwise $=0$ & & & $-0.011 * *$ & 0.008 \\
\hline North-East $=1$, otherwise $=0$ & & & -0.001 & 0.009 \\
\hline Centre $=1$, otherwise $=0$ & & & -0.008 & 0.008 \\
\hline $\begin{array}{l}\text { Failed high school year=1, } \\
\text { otherwise }=0\end{array}$ & & & $-0.100 *$ & 0.008 \\
\hline \multicolumn{5}{|c|}{ High school degree classification- Reference category is 90-100 } \\
\hline $60-69=1$, otherwise $=0$ & & & $-0.248^{*}$ & 0.009 \\
\hline $70-79=1$, otherwise $=0$ & & & $-0.139 *$ & 0.009 \\
\hline $80-89=1$, otherwise $=0$ & & & $-0.051 *$ & 0.010 \\
\hline \multicolumn{5}{|c|}{ Performance at lower secondary school- Reference category is excellent } \\
\hline Pass $=1$, otherwise $=0$ & & & $-0.089 *$ & 0.011 \\
\hline Good $=1$, otherwise $=0$ & & & $-0.042 *$ & 0.010 \\
\hline Very good $=1$, otherwise $=0$ & & & 0.001 & 0.009 \\
\hline $\begin{array}{l}\text { Private high school=1, } \\
\text { otherwise }=0\end{array}$ & & & $-0.052 *$ & 0.014 \\
\hline \multicolumn{5}{|c|}{ Type of high school- Reference category is General } \\
\hline Professional $=1$, otherwise $=0$ & & & $-0.557 *$ & 0.011 \\
\hline Technical $=1$, otherwise $=0$ & & & $-0.353 *$ & 0.008 \\
\hline Artistic $==1$, , otherwise $=0$ & & & $-0.513^{*}$ & 0.017 \\
\hline \multicolumn{5}{|c|}{ Father's education- Reference category is University } \\
\hline $\begin{array}{l}\text { Primary school or less }=1 \text {, } \\
\text { otherwise }=0\end{array}$ & & & $-0.061^{*}$ & 0.015 \\
\hline $\begin{array}{l}\text { Lower secondary school=1, } \\
\text { otherwise }=0\end{array}$ & & & $-0.038 *$ & 0.013 \\
\hline High school=1, otherwise $=0$ & & & 0.008 & 0.012 \\
\hline \multicolumn{5}{|c|}{ Mother's education- Reference category is University } \\
\hline $\begin{array}{l}\text { Primary school or less }=1, \\
\text { otherwise }=0\end{array}$ & & & $-0.115^{*}$ & 0.014 \\
\hline $\begin{array}{l}\text { Lower secondary school=1, } \\
\text { otherwise }=0\end{array}$ & & & $-0.075^{*}$ & 0.012 \\
\hline High school=1, otherwise $=0$ & & & -0.010 & 0.011 \\
\hline \multicolumn{5}{|c|}{ Father's occupation- Reference category is High-level } \\
\hline Medium-level=1, otherwise $=0$ & & & $-0.026^{*}$ & 0.009 \\
\hline Low-level $=1$, otherwise $=0$ & & & $-0.076^{*}$ & 0.010 \\
\hline Other-unknown $=1$, otherwise $=0$ & & & -0.030 & 0.019 \\
\hline R-squared & 0.023 & & 0.438 & \\
\hline Number of observations & 16,959 & & 16,959 & \\
\hline
\end{tabular}

* denotes statistically significant at the $1 \%$ level

** denotes statistically significant at the $5 \%$ level

*** denotes statistically significant at the $10 \%$ level

Survey weights are used in the regression analysis 
Table 6- Effect of the abolition of military conscription on university enrolment: triple-difference estimates

\begin{tabular}{|c|c|c|c|c|}
\hline & Coefficient & Standard Error & Coefficient & Standard Error \\
\hline Constant & $0.607 *$ & 0.005 & $1.132 *$ & 0.009 \\
\hline $\begin{array}{l}\text { Aged } 18 \text { or less when finished high } \\
\text { school=1, otherwise } 0\end{array}$ & $0.225^{*}$ & 0.019 & $-0.028 * * *$ & 0.015 \\
\hline Male $=1$, otherwise 0 & $-0.087 *$ & 0.007 & 0.009 & 0.006 \\
\hline $\begin{array}{l}\text { Aged } 18 \text { or less when finished high } \\
\text { school }=1 \text {, otherwise } 0 * \text { Male }=1 \text {, } \\
\text { otherwise } 0\end{array}$ & $0.062 * *$ & 0.030 & $0.059 * *$ & 0.023 \\
\hline $\begin{array}{l}\text { Finished high school in 2004=1, } \\
\text { otherwise } 0\end{array}$ & $0.033^{*}$ & 0.007 & $0.023^{*}$ & 0.006 \\
\hline $\begin{array}{l}\text { Finished high school in } 2004=1 \text {, } \\
\text { otherwise } 0 * \text { Male }=1 \text {, otherwise } 0\end{array}$ & $-0.038 *$ & 0.010 & $-0.025 *$ & 0.008 \\
\hline $\begin{array}{l}\text { Finished high school in } 2004=1 \text {, } \\
\text { otherwise } 0 * \text { Aged } 18 \text { or less when } \\
\text { finished high school=1, otherwise } 0\end{array}$ & $-0.078 *$ & 0.029 & -0.025 & 0.022 \\
\hline $\begin{array}{l}\text { Aged } 18 \text { or less when finished high } \\
\text { school }=1 \text {, otherwise } 0 * \text { Male }=1 \text {, } \\
\text { otherwise } 0 * \text { Finished high school } \\
\text { in } 2004=1 \text {, otherwise } 0\end{array}$ & $0.089 * *$ & 0.043 & 0.033 & 0.033 \\
\hline \multicolumn{5}{|c|}{ Area of residence-Reference category is South } \\
\hline North-West $=1$, otherwise $=0$ & & & 0.009 & 0.005 \\
\hline North-East $=1$, otherwise $=0$ & & & -0.003 & 0.006 \\
\hline Centre $=1$, otherwise $=0$ & & & -0.002 & 0.005 \\
\hline $\begin{array}{l}\text { Failed high school year }=1 \text {, } \\
\text { otherwise }=0\end{array}$ & & & $-0.085 *$ & 0.005 \\
\hline \multicolumn{5}{|c|}{ High school degree classification- Reference category is $90-100$} \\
\hline $60-69=1$, otherwise $=0$ & & & $-0.249 *$ & 0.006 \\
\hline $70-79=1$, otherwise $=0$ & & & $-0.142 *$ & 0.006 \\
\hline $80-89=1$, otherwise $=0$ & & & $-0.063^{*}$ & 0.006 \\
\hline \multicolumn{5}{|c|}{ Performance at lower secondary school- Reference category is excellent } \\
\hline Pass $=1$, otherwise $=0$ & & & $-0.110^{*}$ & 0.008 \\
\hline Good $=1$, otherwise $=0$ & & & $-0.042 *$ & 0.007 \\
\hline Very good $=1$, otherwise $=0$ & & & 0.007 & 0.006 \\
\hline $\begin{array}{l}\text { Private high school=1, otherwise= } \\
0\end{array}$ & & & $-0.071 *$ & 0.009 \\
\hline \multicolumn{5}{|c|}{ Type of high school- Reference category is General } \\
\hline Professional $=1$, otherwise $=0$ & & & $-0.524 *$ & 0.007 \\
\hline Technical $=1$, otherwise $=0$ & & & $-0.329 *$ & 0.005 \\
\hline Artistic $==1$, , otherwise $=0$ & & & $-0.469 *$ & 0.011 \\
\hline \multicolumn{5}{|c|}{ Father's education- Reference category is University } \\
\hline $\begin{array}{l}\text { Primary school or less }=1, \\
\text { otherwise }=0\end{array}$ & & & $-0.085^{*}$ & 0.010 \\
\hline $\begin{array}{l}\text { Lower secondary school=1, } \\
\text { otherwise }=0\end{array}$ & & & $-0.052 *$ & 0.009 \\
\hline High school $=1$, otherwise $=0$ & & & -0.006 & 0.008 \\
\hline \multicolumn{5}{|c|}{ Mother's education- Reference category is University } \\
\hline $\begin{array}{l}\text { Primary school or less }=1, \\
\text { otherwise }=0\end{array}$ & & & $-0.118 *$ & 0.010 \\
\hline $\begin{array}{l}\text { Lower secondary school=1, } \\
\text { otherwise }=0\end{array}$ & & & $-0.073 *$ & 0.008 \\
\hline High school $=1$, otherwise $=0$ & & & -0.007 & 0.008 \\
\hline \multicolumn{5}{|c|}{ Father's occupation- Reference category is High-level } \\
\hline Medium-level $=1$, otherwise $=0$ & & & $-0.019 *$ & 0.006 \\
\hline Low-level $=1$, otherwise $=0$ & & & $-0.065^{*}$ & 0.007 \\
\hline Other-unknown $=1$, otherwise $=0$ & & & $-0.063 *$ & 0.013 \\
\hline R-squared & 0.025 & & 0.422 & \\
\hline Number of observations & 37,805 & & 37,805 & \\
\hline
\end{tabular}


Table 7- Effect of the abolition of military conscription on university enrolment: triple-difference estimates- heterogeneous effects

\begin{tabular}{|c|c|c|c|c|}
\hline & \multicolumn{2}{|c|}{$\begin{array}{l}\text { High school graduates whose } \\
\text { father's occupation is High- } \\
\text { level or Medium-level }\end{array}$} & \multicolumn{2}{|c|}{$\begin{array}{c}\text { High school graduates whose father’s } \\
\text { occupation is Low-level or } \\
\text { Other/unknown }\end{array}$} \\
\hline & Coefficient & Standard Error & Coefficient & Standard Error \\
\hline Constant & $1.096 *$ & 0.010 & $1.267^{*}$ & 0.038 \\
\hline $\begin{array}{l}\text { Aged } 18 \text { or less when finished high } \\
\text { school=1, otherwise } 0\end{array}$ & -0.004 & 0.018 & $-0.081 *$ & 0.031 \\
\hline Male $=1$, otherwise 0 & 0.012 & 0.008 & 0.006 & 0.009 \\
\hline $\begin{array}{l}\text { Aged } 18 \text { or less when finished high } \\
\text { school }=1 \text {, otherwise } 0 * \text { Male }=1 \text {, } \\
\text { otherwise } 0\end{array}$ & -0.0004 & 0.027 & $0.250^{*}$ & 0.049 \\
\hline $\begin{array}{l}\text { Finished high school in 2004=1, } \\
\text { otherwise } 0\end{array}$ & 0.012 & 0.008 & $0.037 *$ & 0.009 \\
\hline $\begin{array}{l}\text { Finished high school in 2004=1, } \\
\text { otherwise } 0 * \text { Male=1, otherwise } 0\end{array}$ & -0.010 & 0.011 & $-0.044 *$ & 0.012 \\
\hline $\begin{array}{l}\text { Finished high school in } 2004=1 \text {, } \\
\text { otherwise } 0 * \text { Aged } 18 \text { or less when } \\
\text { finished high school=1, otherwise } 0\end{array}$ & -0.038 & 0.025 & 0.056 & 0.046 \\
\hline $\begin{array}{l}\text { Aged } 18 \text { or less when finished high } \\
\text { school }=1 \text {, otherwise } 0 * \text { Male }=1 \text {, } \\
\text { otherwise } 0 * \text { Finished high school } \\
\text { in } 2004=1 \text {, otherwise } 0\end{array}$ & $0.070^{* * *}$ & 0.038 & $-0.144^{* *}$ & 0.070 \\
\hline \multicolumn{5}{|c|}{ Area of residence-Reference category is South } \\
\hline North-West $=1$, otherwise $=0$ & $0.013 * * *$ & 0.007 & 0.004 & 0.008 \\
\hline North-East $=1$, otherwise $=0$ & 0.009 & 0.008 & $-0.018 * *$ & 0.009 \\
\hline Centre $=1$, otherwise $=0$ & -0.005 & 0.007 & 0.005 & 0.008 \\
\hline $\begin{array}{l}\text { Failed high school year }=1, \\
\text { otherwise }=0\end{array}$ & $-0.092 *$ & 0.007 & $-0.077 *$ & 0.008 \\
\hline \multicolumn{5}{|c|}{ High school degree classification- Reference category is 90-100 } \\
\hline $60-69=1$, otherwise $=0$ & $-0.223 *$ & 0.008 & $-0.291 *$ & 0.010 \\
\hline $70-79=1$, otherwise $=0$ & $-0.112 *$ & 0.008 & $-0.190 *$ & 0.010 \\
\hline $80-89=1$, otherwise $=0$ & $-0.044 *$ & 0.008 & $-0.098 *$ & 0.010 \\
\hline \multicolumn{5}{|c|}{ Performance at lower secondary school-Reference category is excellent } \\
\hline Pass $=1$, otherwise $=0$ & $-0.107 *$ & 0.010 & $-0.123 *$ & 0.012 \\
\hline Good $=1$, otherwise $=0$ & $-0.033^{*}$ & 0.008 & $-0.065^{*}$ & 0.011 \\
\hline Very good $=1$, otherwise $=0$ & $0.019 * *$ & 0.008 & $-0.024 * *$ & 0.010 \\
\hline $\begin{array}{l}\text { Private high school=1, otherwise }= \\
0\end{array}$ & $-0.058 *$ & 0.010 & & \\
\hline \multicolumn{5}{|c|}{ Type of high school- Reference category is General } \\
\hline Professional $=1$, otherwise $=0$ & $-0.512 *$ & 0.010 & $-0.561 *$ & 0.011 \\
\hline Technical $=1$, otherwise $=0$ & $-0.296 *$ & 0.007 & $-0.391 *$ & 0.009 \\
\hline Artistic $==1$, , otherwise $=0$ & $-0.446 *$ & 0.015 & $-0.521 *$ & 0.017 \\
\hline \multicolumn{5}{|c|}{ Father's education- Reference category is University } \\
\hline $\begin{array}{l}\text { Primary school or less }=1, \\
\text { otherwise }=0\end{array}$ & $-0.109 *$ & 0.014 & $-0.148^{*}$ & 0.038 \\
\hline $\begin{array}{l}\text { Lower secondary school=1, } \\
\text { otherwise }=0\end{array}$ & $-0.076^{*}$ & 0.009 & $-0.116^{*}$ & 0.037 \\
\hline High school $=1$, otherwise $=0$ & $-0.024 *$ & 0.008 & $-0.080 * *$ & 0.037 \\
\hline \multicolumn{5}{|c|}{ Mother's education- Reference category is University } \\
\hline $\begin{array}{l}\text { Primary school or less }=1, \\
\text { otherwise }=0\end{array}$ & $-0.122 *$ & 0.013 & $-0.154 *$ & 0.023 \\
\hline $\begin{array}{l}\text { Lower secondary school=1, } \\
\text { otherwise }=0\end{array}$ & $-0.072 *$ & 0.010 & $-0.116 *$ & 0.022 \\
\hline High school $=1$, otherwise $=0$ & -0.009 & 0.008 & $-0.047 * *$ & 0.022 \\
\hline R-squared & 0.403 & & 0.370 & \\
\hline Number of observations & 20,207 & & 17,598 & \\
\hline
\end{tabular}

